\title{
Bartonella japonica sp. nov. and Bartonella silvatica sp. nov., isolated from Apodemus mice
}

Correspondence

Soichi Maruyama maruyama.soichi@nihon-u.ac.jp

\author{
Kai Inoue, ${ }^{1}$ Hidenori Kabeya, ${ }^{1}$ Hatsumi Shiratori, ${ }^{2}$ Kenji Ueda, ${ }^{2}$ \\ Michael Y. Kosoy, ${ }^{3}$ Bruno B. Chomel, ${ }^{4}$ Henri-Jean Boulouis ${ }^{5}$ \\ and Soichi Maruyama ${ }^{1}$
}

${ }^{1}$ Laboratory of Veterinary Public Health, Department of Veterinary Medicine, College of Bioresource Sciences, Nihon University, 1866 Kameino, Fujisawa, Kanagawa 252-8510, Japan

${ }^{2}$ Life Science Research Center, College of Bioresource Sciences, Nihon University, Fujisawa, Kanagawa 252-8510, Japan

${ }^{3}$ Division of Vector-Borne Infectious Diseases, National Center for Infectious Diseases, Centers for Disease Control and Prevention, Fort Collins, CO 80521, USA

${ }^{4}$ Department of Population Health and Reproduction, School of Veterinary Medicine, University of California, Davis, CA 95616, USA

${ }^{5}$ UMR BIPAR/AFSSA, Institut National de la Recherche Agronomique, Ecole Nationale Vétérinaire d'Alfort/UVPM, 7 avenue du Général de Gaulle, 94704 Maisons-Alfort Cedex, France

Two bacterial strains, Fuji $18-1^{\top}$ and Fuji $23-1^{\top}$, were isolated from the blood of the small Japanese field mouse (Apodemus argenteus) and the large Japanese field mouse (Apodemus speciosus), respectively, specimens of which were captured in the forest of Mount Fuji, Japan. Phenotypic characterization (growth conditions, incubation periods, biochemical properties and cell morphologies), DNA G $+C$ contents (40.1 mol\% for strain Fuji $18-1^{\top}$ and $40.4 \mathrm{~mol} \%$ for strain Fuji $23-1^{\top}$ ) and sequence analyses of the 16S rRNA genes indicated that both strains were members of the genus Bartonella. Using $r p o B$ and $g / t A$ sequencing analysis, the highest sequence similarities between strains Fuji $18-1^{\top}$, Fuji $23-1^{\top}$ and other recognized species of the genus Bartonella showed values considerably lower than $91.4 \%$ and $89.9 \%$ in the rpoB gene and $89.1 \%$ and $90.4 \%$ in the glt $A$ gene, respectively. It is known that similarities of $95.4 \%$ for the $r p o B$ gene and $96.0 \%$ for the $g / t A$ gene can be applied as cut-off values for the designation of novel species of the genus Bartonella. In a phylogenetic tree based on the merged set of concatenated sequences of seven loci [16S rRNA, ftsZ, glt $A$, groEL, ribC and rpo $B$ genes and the intergenic spacer region (ITS)], strains Fuji $18-1^{\top}$ and Fuji $23-1^{\top}$ formed a distinct clade from other recognized species of the genus Bartonella. These data support the classification of strains Fuji $18-1^{\top}$ and Fuji $23-1^{\top}$ as novel species of the genus Bartonella. The names Bartonella japonica sp. nov. and Bartonella silvatica sp. nov. are proposed for these novel species. The type strains of Bartonella japonica sp. nov. and Bartonella silvatica sp. nov. are Fuji $18-1^{\top}\left(=\mathrm{JCM} 15567^{\top}=\mathrm{CIP} 109861^{\top}\right)$ and Fuji $23-1^{\top}\left(=\mathrm{JCM} 15566^{\top}=\mathrm{CIP} 109862^{\top}\right)$, respectively.

\footnotetext{
Abbreviations: ITS, intergenic spacer region; MP, maximum-parsimony; NJ, neighbour-joining.
}

The GenBank accession numbers for the 16S rRNA, ftsZ, gltA, groEL, ribC and rpoB genes and the 16S-23S rRNA intergenic spacer region (ITS) from Bartonella japonica sp. nov. Fuji 18-1 ${ }^{\top}$ are AB440632, AB440633, AB242289, AB440634, AB440635, AB242288, and AB498007, respectively. GenBank accession numbers for the $16 \mathrm{~S}$ rRNA, ftsZ, gltA, groEL, ribC and rpoB genes and ITS sequences from Bartonella silvatica sp. nov. Fuji 23-1 ${ }^{\top}$ are AB440636, AB440637, AB242287, AB440638, AB440639, AB242292, and AB498008, respectively.

Sequence similarities of the $16 \mathrm{~S}$ rRNA, ftsZ, gltA, groEL, ribC and rpoB genes and ITS region sequences between strains Fuji 18-1 $1^{\top}$, Fuji 23-1 ${ }^{\top}$ and other species of the genus Bartonella, a maximum-parsimony phylogenetic tree based on the concatenated sequence of the seven loci and neighbour-joining trees of the seven loci are available as supplementary material with the online version of this paper. 
The genus Bartonella is classified in the class Alphaproteobacteria, order Rhizobiales and family Bartonellaceae and, at the time of writing, comprised 19 recognized species and three subspecies. The bacteria in the genus Bartonella are small, fastidious, slow-growing Gram-negative rods (Brenner et al., 1993; Birtles et al., 1995). Species of the genus Bartonella are known to infect erythrocytes and endothelial cells of various mammals, such as humans, cats, dogs, ruminants, wild rabbits and wild rodents (Dehio, 2005). We previously described the prevalence of species of the genus Bartonella among 685 wild rodents in Japan (Inoue et al., 2008). Based on phylogenetic trees constructed with the $r p o B$ and gltA gene sequences and the criteria for the definition of a species of the genus Bartonella (La Scola et al., 2003), two strains were identified as possible novel species of this genus. Strains Fuji $18-1^{\mathrm{T}}$ and Fuji $23-1^{\mathrm{T}}$ were isolated from Apodemus argenteus and Apodemus speciosus mice captured in the Mount Fuji forest in Japan. In the present study, these strains were characterized by biochemical, morphological and genetic approaches, including multilocus sequencing analysis of six housekeeping genes and the 16S-23S rRNA intergenic spacer region (ITS).

Strains Fuji $18-1^{\mathrm{T}}$ and Fuji $23-1^{\mathrm{T}}$ were grown on heart infusion agar plates (HIA; Difco) containing $5 \%(\mathrm{w} / \mathrm{v})$ defibrinated rabbit blood at $35{ }^{\circ} \mathrm{C}$ with $5 \% \mathrm{CO}_{2}$ for 14 days. Gram staining was assessed by light microscopy (Olympus) at $\times 1000$ magnification. Cell morphology was observed by transmission electron microscopy (model JEM1200EX; JEOL) at $100 \mathrm{kV}$ with negative staining.

Biochemical characteristics were assessed by using a MicroScan Rapid Anaerobe Panel (Dade Behring Inc.) according to the manufacturer's instructions as described previously (Welch et al., 1993). Cytochrome oxidase test strips (Nissui) were used for evaluating the oxidase activity of the strains. Catalase activity was examined by mixing fresh colonies which had been cultured for 14 days at $35{ }^{\circ} \mathrm{C}$ on $5 \%$ rabbit blood chocolate HIA plates with $3 \% \mathrm{H}_{2} \mathrm{O}_{2}$ on a glass slide.

DNA G + C content was determined by HPLC (Mesbah \& Whitman, 1989). Mean values of the $G+C$ content $( \pm \mathrm{SD})$ were calculated based on assays conducted in triplicate.

Genomic DNA was extracted using the Instagene Matrix (Bio-Rad) according to the manufacturer's instructions. Six housekeeping genes, $16 \mathrm{~S}$ rRNA, ftsZ, gltA, groEL, ribC and $r p o B$, and ITS fragments were amplified by PCR as previously described (Birtles \& Raoult, 1996; Heller et al., 1997; Renesto et al., 2001; Houpikian \& Raoult, 2001; Zeaiter et al., 2002a, b; Inoue et al., 2009). The PCR products were purified using a Spin Column PCR Product Purification kit (Bio Basic). Direct DNA sequencing of the purified PCR products was performed using the BigDye Terminator Cycle Sequencing Ready Reaction kit (Applied Biosystems) on a Genetic Analyzer (model 3130; Applied Biosystems). For the phylogenetic analysis, sequence data were aligned with those of type strains of other species of the genus Bartonella (Table 1) that were available in GenBank by using CLUSTAL w software (Thompson et al., 1994) in the MEGA4 program (Tamura et al., 2007). Phylogenetic trees based on six housekeeping genes and the ITS region were constructed using the neighbour-joining (NJ) method (Saitou \& Nei, 1987). The nucleotide substitution rates were calculated by Kimura's two-parameter distance model (Kimura, 1980). Bootstrap analysis was carried out on 1000 replications of the dataset (Felsenstein, 1985). Brucella melitensis $16 \mathrm{M}^{\mathrm{T}}$ was chosen as the outgroup. The phylogenetic trees of the concatenated sequence data for the 16S rRNA, ftsZ, gltA, groEL, ribC and $r p o B$ genes and the ITS region were constructed using the $\mathrm{NJ}$ and maximum-parsimony (MP) methods (Fitch, 1971) with the Jukes-Cantor parameter model (Jukes \& Cantor, 1969) by using the MEGA4 program.

Strains Fuji $18-1^{\mathrm{T}}$ and Fuji $23-1^{\mathrm{T}}$ grown on HIA formed smooth, transparent to grey-whitish colonies of 1-2 $\mathrm{mm}$ in diameter. Gram-negative coccobacilli to short rod-shaped cells were observed by light microscopy after 14 days culture. The cell morphologies of both strains were similar and no flagella or pili were observed by electron microscopy (Fig. 1). Cell sizes were $0.74 \mu \mathrm{m}$ in length and $0.36 \mu \mathrm{m}$ in width for strain Fuji $18-1^{\mathrm{T}}$ and $1.16 \mu \mathrm{m}$ in length and $0.43 \mu \mathrm{m}$ in width for strain Fuji $23-1^{\mathrm{T}}$.

Both strains were oxidase- and catalase-negative and neither exhibited urease activity nor hydrolysed trehalose. They both hydrolysed bis- $p$-nitrophenyl phosphate, but not $p$-nitrophenyl $N$-acetyl $\beta$-D-glucosaminide. Both strains had amino acid arylamidase activity towards leucine, methionine, lysine (alkaline as well as acidic), glycine, arginine and tryptophan. Strain Fuji 23-1 ${ }^{\mathrm{T}}$ exhibited L-proline- $\beta$-naphthylamide activity but strain Fuji $18-1^{\mathrm{T}}$ did not. Both strains had glycylglycylarylamidase activity, but not pyrrolidonyl arylamidase activity. These biochemical results are typical for members of the genus Bartonella (Bermond et al., 2000, 2002; Maillard et al., 2004); however, the profiles cannot be applied routinely and reliably for the differentiation of species of the genus Bartonella because of the relatively inert nature of bartonellae (Dehio et al., 2001; Bermond et al., 2002).

The DNA G $+\mathrm{C}$ contents of strains Fuji $18-1^{\mathrm{T}}$ and Fuji $23-1^{\mathrm{T}}$ were $40.1 \pm 0.6 \mathrm{~mol} \%($ mean $\pm \mathrm{SD})$ and $40.4 \pm 0.5 \mathrm{~mol} \%$ (mean $\pm \mathrm{SD}$ ), respectively. These values were similar to those of other species of the genus Bartonella (Bermond et al., 2000, 2002).

DNA fragments of all seven loci examined were sequenced and the sequence data were compared with the type strains of other species of the genus Bartonella. The $16 \mathrm{~S}$ rRNA gene sequence similarities of strains Fuji $18-1^{\mathrm{T}}$ and Fuji $23-1^{\mathrm{T}}$ to other Bartonella species ranged from $96.5 \%$ (Bartonella bacilliformis) to $98.8 \%$ (Bartonella grahamii) and $96.7 \%$ (Bartonella bacilliformis) to $98.8 \%$ (Bartonella koehlerae), respectively (see Supplementary Table S1 in IJSEM Online). 
Table 1. GenBank accession numbers of the seven loci for the Bartonella species used in this study

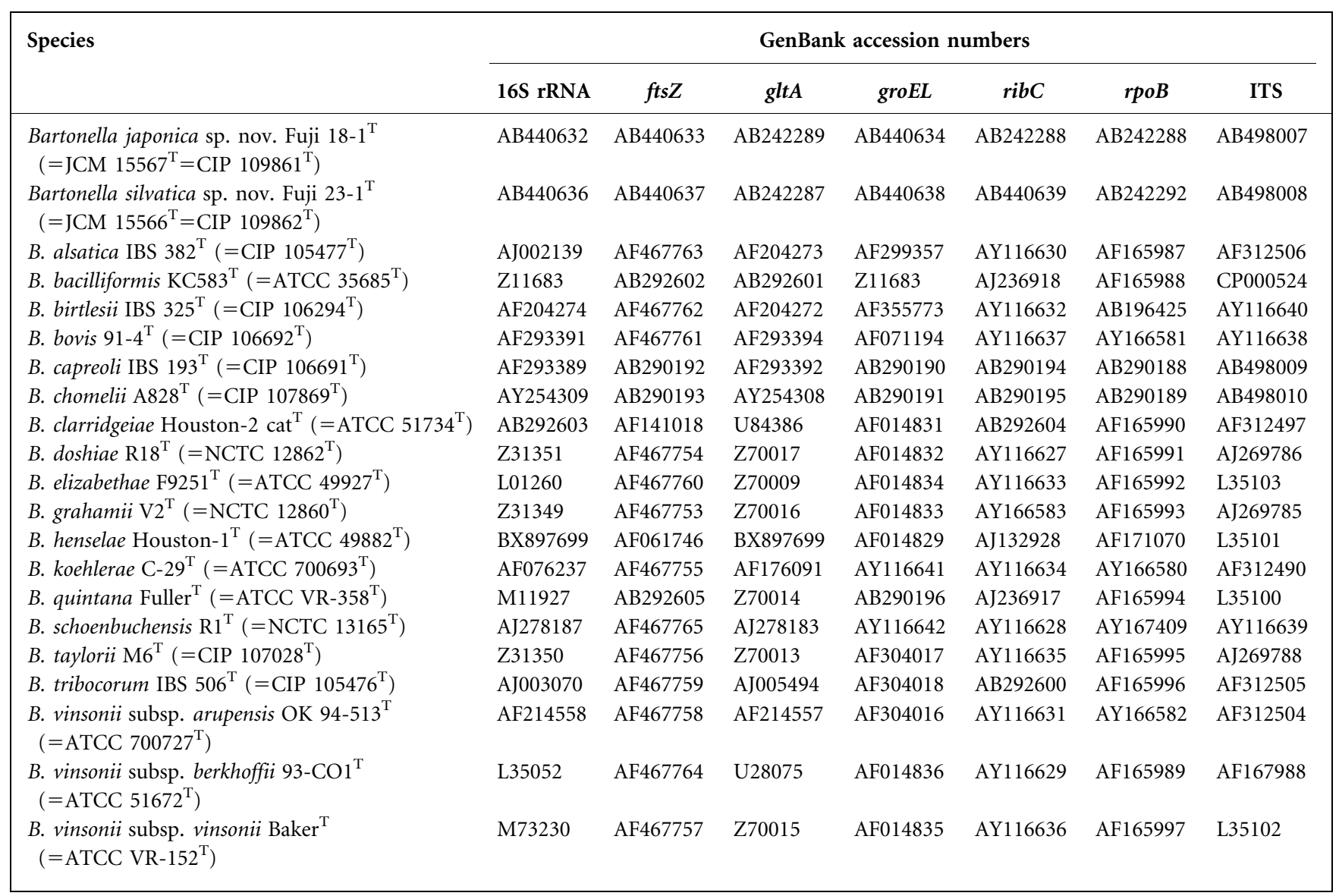

La Scola et al. (2003) reported that $r p o B$ and gltA were the most appropriate genes for discriminating species of the genus Bartonella and proposed that gene sequence similarities $<95.4 \%$ in $r p o B$ and $<96.0 \%$ in glt $A$ between recognized species of the genus Bartonella could be used as cut-off values for the designation of novel Bartonella species. The highest sequence similarities between strains Fuji $18-1^{\mathrm{T}}$, Fuji $23-1^{\mathrm{T}}$ and other species of the genus Bartonella showed values considerably lower than $91.4 \%$ (strain Fuji $18-1^{\mathrm{T}}$ compared with Bartonella alsatica) and $89.9 \%$ (strain Fuji $23-1^{\mathrm{T}} / B$. alsatica) for the $r p o B$ gene and $89.1 \%$ (strain Fuji $18-1^{\mathrm{T}} /$ Bartonella vinsonii subsp. arupensis) and $90.4 \%$ (strain Fuji $23-1^{\mathrm{T}} /$ Bartonella taylorii) for the gltA gene. Thus, strains Fuji $18-1^{\mathrm{T}}$ and Fuji $23-1^{\mathrm{T}}$ fulfil the requirements for classification as novel species of the genus Bartonella.

Strains Fuji $18-1^{\mathrm{T}}$ and Fuji $23-1^{\mathrm{T}}$ also showed considerably lower gene sequence similarities for the remaining four loci, fts $Z$, groEL, ribC and ITS, when compared with other recognized species of the genus Bartonella (Supplementary Table S1). In the phylogenetic tree based on the merged set of concatenated sequences of seven loci, strains Fuji $18-1^{\mathrm{T}}$ and Fuji $23-1^{\mathrm{T}}$ formed a distinct clade with other species of the genus Bartonella (Fig. 2). The MP tree based on the concatenated sequence of the seven loci and the NJ trees based on sequence analyses of the seven loci also revealed that strains Fuji $18-1^{\mathrm{T}}$ and Fuji $23-1^{\mathrm{T}}$ were clearly separated from all other species of the genus Bartonella (see Supplementary Figs S1 and S2 in IJSEM Online).

In conclusion, sequence similarities of the $r p o B$ and glt $A$ genes and the phylogenetic analyses of seven different loci support the classification of strains Fuji $18-1^{\mathrm{T}}$ and Fuji $23-1^{\mathrm{T}}$ as novel species of the genus Bartonella, for which we propose the names Bartonella japonica sp. nov. and Bartonella silvatica sp. nov., respectively.

\section{Description of Bartonella japonica sp. nov.}

Bartonella japonica [ja.po'ni.ca. N.L. fem. adj. japonica of Japan, where the host rodent, the small Japanese field mouse (Apodemus argenteus), from which the strain was isolated, is widely distributed].

After 14 days incubation on HIA at $35{ }^{\circ} \mathrm{C}$ in a moist atmosphere under $5 \% \mathrm{CO}_{2}$, colonies appear small (1$2 \mathrm{~mm}$ in diameter), round, grey-whitish and smooth. Cells are small bacilli without flagella or pili and are $0.74 \times 0.36 \mu \mathrm{m}$. Oxidase- and catalase-negative, does not exhibit urease activity or hydrolyse trehalose. Hydrolyses bis- $p$-nitrophenyl phosphate but not $p$-nitrophenyl $N$ acetyl $\beta$-D-glucosaminide. Exhibits arylamidase activity 


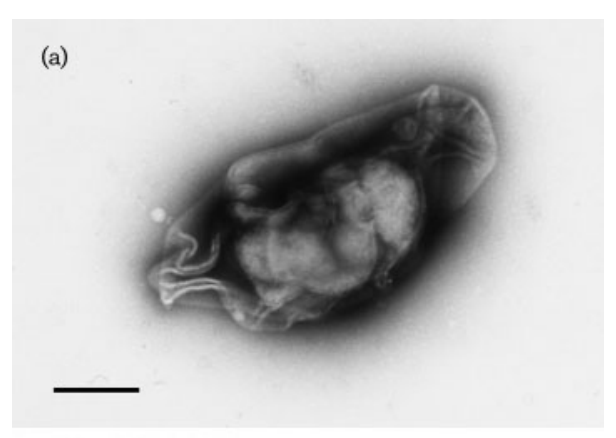

(b)

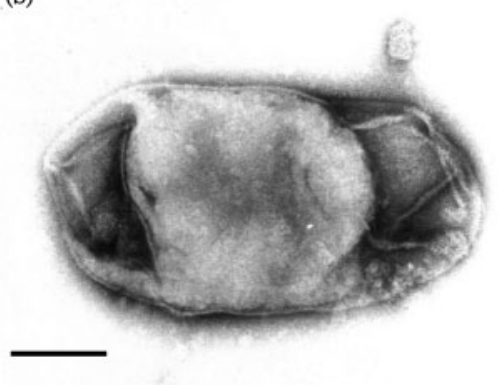

Fig. 1. Transmission electron micrograph of cells of (a) Bartonella japonica sp. nov. strain Fuji $18-1^{\top}$ and (b) Bartonella silvatica sp. nov. strain Fuji $23-1^{\top}$. Bars, $200 \mathrm{~nm}$.

towards leucine, methionine, lysine (alkaline as well as acidic), glycine, arginine and tryptophan, but not to proline. Glycylglycylarylamidase activity is present, but no pyrrolidonyl arylamidase activity. Can be distinguished from other species of the genus Bartonella by the $16 \mathrm{~S}$ rRNA, fts $Z$, glt $A$, groEL, ribC and $r p o B$ gene and ITS region sequences.
The type strain, Fuji $18-1^{\mathrm{T}}\left(=\mathrm{JCM} 15567^{\mathrm{T}}=\mathrm{CIP} 109861^{\mathrm{T}}\right)$, was isolated from the blood of Apodemus argenteus mice. The DNA G $+\mathrm{C}$ content of the type strain is $40.1 \mathrm{~mol} \%$.

\section{Description of Bartonella silvatica sp. nov.}

Bartonella silvatica [sil.va'ti.ca. L. fem. adj. silvatica of the forest where the host rodent, the large Japanese field mouse (Apodemus speciosus), from which the strain was isolated, was captured].

After 14 days incubation on HIA at $35{ }^{\circ} \mathrm{C}$ in a moist atmosphere under $5 \% \mathrm{CO}_{2}$, colonies appear small (1-2 mm in diameter), round, grey-whitish and smooth. Cells are small bacilli without flagella or pili and are $1.16 \times 0.43 \mu \mathrm{m}$. Oxidase- and catalase-negative. Does not exhibit urease activity or hydrolyse trehalose. Hydrolyses bis- $p$-nitrophenyl phosphate but not $p$-nitrophenyl $N$-acetyl $\beta$-D-glucosaminide. Exhibits arylamidase activity towards leucine, methionine, lysine (alkaline as well as acidic), glycine, proline, arginine and tryptophan. Glycylglycylarylamidase activity, but no pyrrolidonyl arylamidase activity. Can be distinguished from other species of the genus Bartonella by the 16S rRNA, fts $Z$, gltA, groEL, ribC and $r p o B$ gene and ITS region sequences.

The type strain, Fuji $23-1^{\mathrm{T}}\left(=\mathrm{JCM} 15566^{\mathrm{T}}=\mathrm{CIP} 109862^{\mathrm{T}}\right)$, was isolated from the blood of Apodemus speciosus mice. The DNA G + C content of the type strain is $40.4 \mathrm{~mol} \%$.

\section{Acknowledgements}

This work was supported in part by grants for the Academic Frontier Project 'Surveillance and Control for Zoonoses' and Grant-in-aid for Scientific Research (20580343) from the Ministry of Education, Culture, Sports, Science and Technology, Japan.

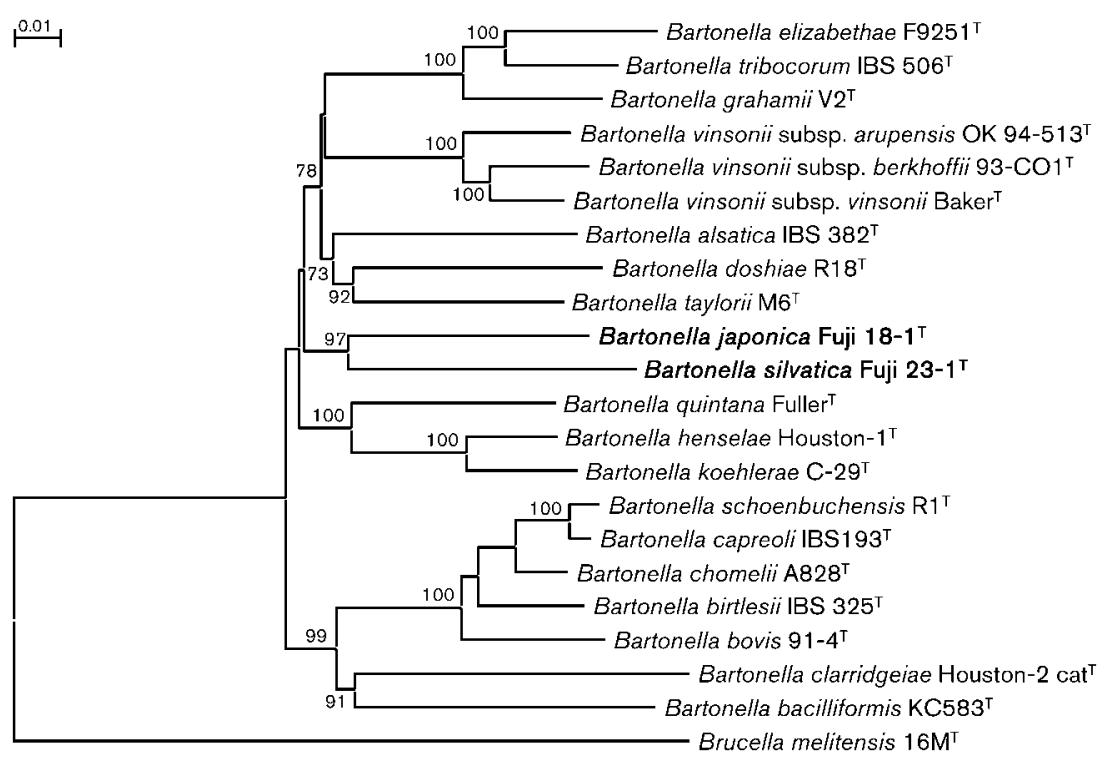

Fig. 2. Phylogenetic relationship of species of the genus Bartonella inferred from concatenated sequences of $16 \mathrm{~S}$ rRNA, ftsZ, gltA, groEL, ribC and $r p o B$ genes and the ITS region. The phylogenetic tree was constructed by using the NJ method with the Jukes-Cantor parameter model. The tree was rooted by the use of Brucella melitensis $16 \mathrm{M}^{\top}$ as an outgroup. Bootstrap values (percentages of 1000 replications) above $70 \%$ are indicated at the nodes. Bar, 0.01 estimated nucleotide substitutions per site. 


\section{References}

Bermond, D., Heller, R., Barrat, F., Delacour, G., Dehio, C., Alliot, A., Monteil, H., Chomel, B., Boulouis, H. J. \& Piemont, Y. (2000). Bartonella birtlesii sp. nov., isolated from small mammals (Apodemus spp.). Int J Syst Evol Microbiol 50, 1973-1979.

Bermond, D., Boulouis, H. J., Heller, R., Van Laere, G., Monteil, H., Chomel, B. B., Sander, A., Dehio, C. \& Piemont, Y. (2002). Bartonella bovis Bermond et al. sp. nov. and Bartonella capreoli sp. nov., isolated from European ruminants. Int J Syst Evol Microbiol 52, 383-390.

Birtles, R. J. \& Raoult, D. (1996). Comparison of partial citrate synthase gene ( gltA) sequences for phylogenetic analysis of Bartonella species. Int J Syst Bacteriol 46, 891-897.

Birtles, R. J., Harrison, T. G., Saunders, N. A. \& Molyneux, D. H. (1995). Proposals to unify the genera Grahamella and Bartonella, with descriptions of Bartonella talpae comb. nov., Bartonella peromysci comb. nov., and three new species, Bartonella grahamii sp. nov., Bartonella taylorii sp. nov., and Bartonella doshiae sp. nov. Int J Syst Bacteriol 45, 1-8.

Brenner, D. J., O'Connor, S. P., Winkler, H. H. \& Steigerwalt, A. G. (1993). Proposals to unify the genera Bartonella and Rochalimaea, with descriptions of Bartonella quintana comb. nov., Bartonella vinsonii comb. nov., Bartonella henselae comb. nov., and Bartonella elizabethae comb. nov., and to remove the family Bartonellaceae from the order Rickettsiales. Int J Syst Bacteriol 43, 777-786.

Dehio, C. (2005). Bartonella-host-cell interactions and vascular tumour formation. Nat Rev Microbiol 3, 621-631.

Dehio, C., Lanz, C., Pohl, R., Behrens, P., Bermond, D., Piemont, Y., Pelz, K. \& Sander, A. (2001). Bartonella schoenbuchii sp. nov., isolated from the blood of wild roe deer. Int J Syst Evol Microbiol 51, 1557-1565.

Felsenstein, J. (1985). Confidence limits on phylogenies: an approach using the bootstrap. Evolution 39, 783-791.

Fitch, W. M. (1971). Toward defining the course of evolution: minimum change for a specific tree topology. Syst Zool 20, 406-416.

Heller, R., Artois, M., Xemar, V., De Briel, D., Gehin, H., Jaulhac, B., Monteil, H. \& Piemont, Y. (1997). Prevalence of Bartonella henselae and Bartonella clarridgeiae in stray cats. J Clin Microbiol 35, 1327-1331.

Houpikian, P. \& Raoult, D. (2001). 16S/23S rRNA intergenic spacer regions for phylogenetic analysis, identification, and subtyping of Bartonella species. J Clin Microbiol 39, 2768-2778.

Inoue, K., Maruyama, S., Kabeya, H., Yamada, N., Ohashi, N., Sato, Y., Yukawa, M., Masuzawa, T., Kawamori, F. \& other authors (2008). Prevalence and genetic diversity of Bartonella species isolated from wild rodents in Japan. Appl Environ Microbiol 74, 5086-5092.
Inoue, K., Kabeya, H., Kosoy, M. Y., Bai, Y., Smirnov, G., McColl, D., Artsob, H. \& Maruyama, S. (2009). Evolutional and geographical relationships of Bartonella grahamii isolates from wild rodents by multi-locus sequencing analysis. Microb Ecol 57, 534-541.

Jukes, T. H. \& Cantor, C. R. (1969). Evolution of protein molecules. In Mammalian Protein Metabolism, vol. 3, pp. 21-132. Edited by H. N. Munro. New York: Academic Press.

Kimura, M. (1980). A simple method for estimating evolutionary rates of base substitutions through comparative studies of nucleotide sequences. J Mol Evol 16, 111-120.

La Scola, B., Zeaiter, Z., Khamis, A. \& Raoult, D. (2003). Genesequence-based criteria for species definition in bacteriology: the Bartonella paradigm. Trends Microbiol 11, 318-321.

Maillard, R., Riegel, P., Barrat, F., Bouillin, C., Thibault, D., Gandoin, C., Halos, L., Demanche, C., Alliot, A. \& other authors (2004). Bartonella chomelii sp. nov., isolated from French domestic cattle (Bos taurus). Int J Syst Evol Microbiol 54, 215-220.

Mesbah, M. \& Whitman, W. B. (1989). Measurement of deoxyguanosine/thymidine ratios in complex mixtures by highperformance liquid chromatography for determination of the mole percentage guanine + cytosine of DNA. J Chromatogr 479, 297306.

Renesto, P., Gouvernet, J., Drancourt, M., Roux, V. \& Raoult, D. (2001). Use of $r p o B$ gene analysis for detection and identification of Bartonella species. J Clin Microbiol 39, 430-437.

Saitou, N. \& Nei, M. (1987). The neighbor-joining method: a new method for reconstructing phylogenetic trees. Mol Biol Evol 4, 406-425.

Tamura, K., Dudley, J., Nei, M. \& Kumar, S. (2007). MEGA4: Molecular evolutionary genetics analysis (MEGA) software version 4.0. Mol Biol Evol 24, 1596-1599.

Thompson, J. D., Higgins, D. G. \& Gibson, T. J. (1994). CLUSTAL W: improving the sensitivity of progressive multiple sequence alignment through sequence weighting, position-specific gap penalties and weight matrix choice. Nucleic Acids Res 22, 4673-4680.

Welch, D. F., Hensel, D. M., Pickett, D. A., San Joaquin, V. H., Robinson, A. \& Slater, L. N. (1993). Bacteremia due to Rochalimaea henselae in a child: practical identification of isolates in the clinical laboratory. J Clin Microbiol 31, 2381-2386.

Zeaiter, Z., Liang, Z. \& Raoult, D. (2002a). Genetic classification and differentiation of Bartonella species based on comparison of partial ftsZ gene sequences. J Clin Microbiol 40, 3641-3647.

Zeaiter, Z., Fournier, P. E., Ogata, H. \& Raoult, D. (2002b). Phylogenetic classification of Bartonella species by comparing groEL sequences. Int J Syst Evol Microbiol 52, 165-171. 